\title{
Qonsequences of Cultural and Behavioral Difference of Tourist: Study of Australian and Indonesian Tourist Who Visit Lombok Island, West Nusa Tenggara
}

\author{
Baiq Handayani Rinuastuti \\ Faculty of Economic and Business, University of Mataram, Indonesia
}

\begin{abstract}
This study aims at identifying behavior differences of Australian tourists and domestic tourists who visit Lombok island, and determining as well as analyzing the Hofstede cultural variables (power distance, individualistic-collectivist, uncertainty avoidance, masculine-feminine, long-term orientation) that may explain the differences in behavioral intention (to have activities, to interact, and to transact) of Australian and domestic tourists. This study was conducted on 160 Australian and domestic tourists who were visiting the island. Sampling was done by convenience sampling. Methods of data analysis were conducted by using t-test and discriminant analysis. The results of this study showed that there are differences in behavioral intentions of Australian travelers and the domestic ones in having activities, interacting, and transacting, and these differences can be explained by the cultural background of the tourists that are based on cultural orientation at the individual level. This study extends the use of CVSCALE and may be considered as an addition to the use of secondary data in determining the value of culture, as well as providing clearer framework on the limits of the relationship of cultural values and the various tourist behaviors.
\end{abstract}

Keywords: Individualist-Collectivists, Longterm orientation, Masculine-feminine, Power distance, Tourist behavior, Uncertainty avoidance

\section{INTRODUCTION}

The diversity in cultural background is becoming one factor that had been believed to be a differentiating factor between the behaviors of the tourists. The differences in language, dressing, culinary, cultural point of view, lifestyle, and various activities which are undertaken commonly found among travelers [1-4]. As an individual who visits a new country or place, a tourist still has certain needs and desires that should be fulfilled. To meet various needs, they perform actions or activities that demonstrate their behavior to meet the needs for in the tourism places until they arrived back in their homeland. Behavioral differences that occur cannot be avoided and will be found by the tourism actors in any tourism sectors [1,5]. In short, understanding what and how the desire and willingness of the tourists as well as their behavior is an important factor for the success of tourism marketing activities [6].

In terms of tourism sector, culture has a significant influence on the consumer or traveler's behavior [7] and the fundamental determinant of a person's desires and behavior [8]. Cultural values is an umbrella concept which

\footnotetext{
* Correspondence address:

Baiq Handayani Rinuastuti

Email : hrinuastuti@yahoo.com

Address : Fac. Economic \& Business, University of Mataram JL. Majapahit 62, Mataram 83125
}

includes various elements such as shared values, beliefs and norms that collectively distinguish a particular group of people from others [1] are resistant to change [9], and remain unclear when at home or when traveling abroad [10]. Such cultural differences among the tourists may result in different attitudes, opinions, emotions, as well as the tendency to make a purchase during their traveling [11]. People from different cultures will have different cultural values and rules of social behavior, perception, and social interaction, which in turn will affect their lifestyle, work patterns, the way how to relax, and the patterns of their consumption behavior [12].

The studies related to national cultural differences and tourist behavior has been widely based on the Horstede's cultural dimensions [1316]. According to Hofstede [7], many Asian countries have a culture that is both collectivist and degree of a version to high uncertainty. Tourist behavior, for example, from Japan, Korea, China, and Indonesia tend to travel in groups $[2,3,17]$. Different with Eastern culture, Western culture is often associated with individualistic cultures and have a low level of uncertainty avoidance. In tourism activities, travelers who have a high individualistic cultural background are usually motivated by hedonism, the comfort, the pursuit of pleasure and fun, sensation, 
stimulation of pleasure, and also self-satisfaction [18].

Researches which have been carried so far has been more emphasis on tourists' behavior differences due to the differences in national culture background based on the Hofstede's score of dimensions. It does not explain the relevance of each dimension of culture on behavior. These dimensions often do not always give effect in the form of behavior that is expected to occur in accordance with Hofstede's scores of cultural dimensions [19].

Hofstede's cultural scores indicate the level of culture from various countries, which is a metrical measurement value of certain dominant culture from certain countries [20]. The use of Hofstede's cultural scores is metrics for measuring the cultural orientation of individuals, resulting in some of the methodological difficulties, and it is often contradictory with the existing Hofstede's scores. Therefore we need a measurement of cultural values on the individual level [12]. Some researchers argued that, marketers are more likely to succeed if they focus directly on consumers' characteristics and instead focus on country's characteristics [21-24].

This study tried to identify the behavioral characteristics of Australian and domestic tourists during their stay in Lombok Island, and further analyzed the relationship between Hofstede's cultural dimensions to tourist behaviors; thus, this was to clarify the relationship between each of Hofstede'ss cultural dimensions with tourist behavior. Therefore, the purposes of this study are:

1. Identifying differences in the behavior of activities, interactions, and transactions of Australian and domestic tourists who visit Lombok Island;

2. Knowing and analyzing Hofstede's cultural variables (power distance, individualcollective, uncertainty avoid-ance, masculine-feminine, and long-term orientation) which explain the difference in intention to behave (activities, interactions, and tran-sactions) of Australian and domestic tourists and who visit Lombok Island.

\section{MATERIALS AND METHODS}

This study employed explanatory survey method, which was to describe and test the proposed hypotheses. The subjects in this study were Australian and domestic tourists who visit Lombok Island. There were 80 tourists both
Australian and domestic each group selected as the samples of the survey. According to Roscoe in Sekaran [25] that size of the sample in the multivariate study is at least 10 times of the number of variables studied. Based on consideration of the characteristics of the tourists who had just settled in a certain period of time and been relatively short, sampling in this study was conducted with the convenience sampling.

Data collection was accommodated through questionnaire, which was given directly to the Australian and domestic tourists. Researchers visited tourism sites, which are representing the four most famous tourism sites in Lombok Island, namely; Senggigi Beach, Gili Trawangan, Kuta Beach, and Gulf of An. The questionnaire contained statements of indicators to express the variables being analyzed in this study, which were measured with a 5-point Likert scale $(1,2$, 3,4 , and 5), from strongly disagree (1) to strongly agree (5). To indentify the differences in tourist behavior between the two countries (Australia and Indonesia), the analysis was conducted through two independent sample t-test and to test whether a variable distance power $\left(X_{1}\right)$, individualist-collectivist $\left(X_{2}\right)$, uncertainty avoidance $\left(X_{3}\right)$, masculine-feminine $\left(X_{4}\right)$, long-term orientation $\left(X_{5}\right)$, explaining the difference in behavior activities $\left(Y_{1}\right)$, the behavior of interactions $\left(Y_{2}\right)$, and the behavior of transactions $\left(Y_{3}\right)$ of the tourists. The testing was conducted through discriminant analysis.

\section{RESULTS AND DISCUSSION}

To give a general overview of the relevance of the respondents in this study, the following description of the respondents in terms of sex, age, and education level.

Based on the presentation of Table 1, it shows that the number or percentage of the respondents between men and women did not differ significantly; that was assumed that both men and women have equal opportunities to have tourism activities. In terms of the age aspect, it is showed that the dominant age group was productive age travelers, between 26-45 years old. This might be due to the possibility of the tourists in that age they have higher productivity or spared income for travel or leisure. Based on the education level, the majority of respondents in both groups had a higher education (above high school). 
Cultural \& Behavioral Difference of Australian and Indonesian Tourist who Visit Lombok (Rinuastuti)

Table 1. Description of Australian and Indonesian Tourists Based on Sex, Age, and Education Level

\begin{tabular}{llcc}
\hline Characteristics of the respondents & Category & Australia (\%) & Indonesia (\%) \\
\hline Sex & Male & 46.3 & 56.3 \\
& Female & 53.8 & 43.8 \\
\hline Age & 18-25 years old & 20.0 & 15.0 \\
& $26-35$ years old & 27.5 & 36.3 \\
& 36-45 years old & 18.8 & 37.5 \\
& $46-55$ years old & 13.8 & 11.2 \\
& $56-65$ years old & 17.5 & - \\
& 66-75 years old & 2.5 & - \\
\hline Education & High schools & 38.7 & 33.7 \\
& Diploma & 16.3 & 10.0 \\
& Bachelor (S1) & 36.3 & 45.0 \\
& Graduates (S2/3) & 8.7 & 11.3 \\
\hline
\end{tabular}

For the descriptions from the respondents of the two groups of tourists towards the Hofstede's cultural variables is presented in Table 2 as follows. The score for the variable PD, IC, UA, $M F$, and LTO in both groups showed the domestic tourists was higher level for the fifth variables of culture than Australian tourists. This means that domestic tourists acceptance of inequality in the distribution of power, collectivity, risk-avoidance, feminine, and tend to have values of prudence, fortitude, perseverance, thrift, respect for tradition, and fulfilling social responsibility.

Table 2. Description from the respondents towards the cultural variables

\begin{tabular}{|c|c|c|c|}
\hline \multirow{2}{*}{ Variables } & & \multicolumn{2}{|c|}{ Average Score for Tourists' Culture } \\
\hline & & Australian & Indonesian \\
\hline \multirow[t]{6}{*}{ Power distance (PD) } & Discussing with the subordinates & 1.83 & 2.15 \\
\hline & Asking for opinion from the subordinates & 1.85 & 2.06 \\
\hline & Interactions with the subordinates & 1.56 & 1.63 \\
\hline & Agreeing with the opinions from the subordinates & 2.09 & 2.53 \\
\hline & Not delegating tasks & 2.23 & 2.79 \\
\hline & Mean & 1.91 & 2.23 \\
\hline \multirow[t]{7}{*}{ Individualist-collectivist (IC) } & Prioritizing group & 3.06 & 4.16 \\
\hline & Loyalty to the group & 2.99 & 3.91 \\
\hline & Rewarding the group & 3.15 & 3.83 \\
\hline & The success of the group & 2.95 & 3.85 \\
\hline & The goals of the group & 3.29 & 3.84 \\
\hline & The support from the group & 2.43 & 3.61 \\
\hline & Mean & 2.98 & 3.87 \\
\hline \multirow[t]{6}{*}{ Uncertainty avoidance (UA) } & Instructions as the guidance & 2.88 & 3.58 \\
\hline & Obeying the rules & 3.08 & 3.84 \\
\hline & Rules as the guidance & 2.90 & 3.69 \\
\hline & Standard procedures as standard of operational & 2.53 & 3.78 \\
\hline & Important guidance & 3.21 & 3.73 \\
\hline & Mean & 2.92 & 3.72 \\
\hline \multirow[t]{5}{*}{ Masculine-feminine (MF) } & Equal career for men-women & 1.93 & 2.0 \\
\hline & Different way to solve the problems & 2.33 & 3.41 \\
\hline & Difficult problems can only be handled by men & 2.23 & 3.09 \\
\hline & Special jobs for men & 3.18 & 3.76 \\
\hline & Mean & 2.42 & 3.24 \\
\hline \multirow[t]{7}{*}{ Long-term orientation (LTO) } & Cost savings & 3.93 & 4.39 \\
\hline & Diligence & 4.01 & 4.45 \\
\hline & Stable personality & 4.08 & 4.36 \\
\hline & Future planning & 3.54 & 4.40 \\
\hline & Sacrifice & 2.90 & 4.06 \\
\hline & Hard work & 4.04 & 4.50 \\
\hline & Mean & 3.75 & 4.36 \\
\hline
\end{tabular}


Various activities undertaken by the Australian and domestic tourists indicated their preferences upon variety of alternative activities to do during the vacation. The following is the inquiries from the respondents towards a variety of activities that they could do during the vacation which are referred by Pizam \& Sussman [10]. Table 3 shows the responses of the Australian tourists and domestic tourists on various preferences of activities performed during their vacation.

Table 3. Description of Respondents' Inquiries

\begin{tabular}{llcc}
\hline \multirow{2}{*}{$\begin{array}{c}\text { Behaviors } \\
\text { Variables }\end{array}$} & & \multicolumn{2}{c}{$\begin{array}{c}\text { Average Score for } \\
\text { Tourists' Behaviors }\end{array}$} \\
\cline { 3 - 4 } Activities & Adventures & 3.90 & 3.06 \\
& Active & 3.74 & 3.25 \\
& Up-to-date & 3.66 & 2.76 \\
& Mean & $\mathbf{3 . 7 7}$ & $\mathbf{3 . 0 2}$ \\
\hline Interactions & Local & 2.91 & 2.95 \\
& attractions & & \\
& Local culinary & 4.24 & 3.56 \\
& Length of visit & 3.40 & 3.20 \\
& Gathering & & \\
& with other & 4.03 & 3.43 \\
& travelers & & \\
& Mean & $\mathbf{3 . 6 6}$ & $\mathbf{3 . 2 9}$ \\
\hline Transactions & Buying & 3.09 & 3.86 \\
& souvenir & & \\
& Buying & 3.08 & 4.03 \\
& handicrafts & & \\
& Shopping & 2.24 & 3.81 \\
& Group & 2.13 & 3.78 \\
& traveling & & \\
& Sending & 2.55 & 2.98 \\
& postcards & & \\
Mean & $\mathbf{2 . 6 2}$ & $\mathbf{3 . 6 9}$ \\
\hline & & & \\
\hline
\end{tabular}

Based on Table 3, Australian tourists tend to have higher intentions to conduct the activities or mobility and interactions as it was compared to the domestic tourists. In terms of transactions behaviors, domestic tourists tend to have higher intense transactions than Australian tourists. Based on the results of two independent samples t-test showed that the existence of significant differences between the two groups related to the behavior of the activities, interactions, and transactions, as shown in the following Table 4:

Table 4. Behavioral Differences of Australian and Indonesian Tourists

\begin{tabular}{lrrr}
\hline \multirow{2}{*}{ Tourists' behaviors } & \multicolumn{3}{c}{ Results of t-test } \\
\cline { 2 - 4 } & t-count & t-table & p-value \\
\hline Activities & 6.791 & 1.97 & 0.000 \\
Interactions & 4.048 & & 0.000 \\
Commercials & 10.305 & & 0.000 \\
\hline
\end{tabular}

Table 4 showed $t$-count $>t$-table and the $\mathrm{p}$ value $(0.000)<$ alpha 0.05 level, it shows significant difference in tourists' behaviors from Australia and Indonesia. Based on the analysis results of testing for the difference which has been concluded that: there are differences in the behavior of the activities, interactions, and transactions between Australia and Indonesian tourists in having tourism activities in Lombok Island.

Results of discriminant analysis to prove whether Hofstede's five cultural variables can explain the differences in behavior intention between Australian and domestic tourists in having activities, interactions, and transactions done by establishing discriminant function. The results of discriminant function through stepwise method for the behaviors of activities, interactions, and transactions are as follows:

$$
\begin{aligned}
& D_{Y_{1}}=-6.415+0.602 X 2+1.313 \times 3 ; \\
& C R^{2}=23.6 \% \\
& D_{Y 2}=-7.820+0.552 X 1+1.098 \times 3+ \\
& 0.748 X 5 ; C R^{2}=29.4 \% \\
& D_{Y_{3}}=-7.023+1.709 \times 2+0.354 X 3 ; \\
& C R^{2}=45.8 \%
\end{aligned}
$$

Discriminant function activity behavior consists of two cultural variables (IC, UA) that may explain the differences in the high-low behavioral intention for the activities of the tourists, with squared canonical correlation of 23.6 percent. This means that 23.6 percent of the diversity of the behaviors which occur between the activities of the tourists can be explained through the discriminant function. The diversity of the established interactions behaviors intention of the discriminant function consists of three cultural variables (PD, UA, LTO), 29.4 percent of the variability can be explained through the discriminant function. In the discriminant function formed to diverse transactions behaviors indicates that there are two cultures (IC, UA) that became the explanatory variables of the tourists transaction behavior, 45.8 percent of the variability can be explained through the discriminant function.

Tourists from a culture that has a low level of uncertainty avoidance is likely to have higher threshold tolerance to risks and uncertainties, which will perform risk reduction behavior in the lower level. Instead, tourists who have a high level of cultural aversion is likely to have a low threshold of tolerance towards risks and uncertainty; therefore the tourists will conduct behavioral risk reduction in high-level [26]. 
Australian tourists tend to be more willing to take risk, be tolerant and open of new things, like innovation and ideas as well as interests in any different matters, more facing something new in the form of goods, new environments as well as new people they met during the vacation. As the active outdoor tourists have been found to be outdoor enthusiasts who enjoy activities such as hiking, backpacking, camping, sailing, fishing, golf, and visiting areas of natural or wilderness $[27,28]$ and spend less time and money on shopping. Instead domestic tourists had higher score for uncertainty avoidance cultures. Uncertainty avoidance is likely to be high on the domestic tourist would encourage them to keep themselves and stay shy away from new things that are not familiar to them, so that they have less interactions with tourists from other countries and engage in activities around the tourist sites.

In a collective society, identity and value of the individual is rooted in the social system over the individual accomplishment or achievement, refers to "societies" in which individuals are integrated into a strong, cohesive in-groups [8]. Therefore, people from individualistic cultures tend to see themselves more independent than the collective society and concerned with the fulfillment of their own individual goals, whereas people from collectivist cultures tend to see themselves as someone who connects with others and put concern with value of the communal goal above their own interests.

The freedom to perform a variety of activities, independence, and to behave towards achieving a personal goal may encourage the tourists to be a more individualistic individual whose values to actualize themselves; they would perform various activities freely without having to think about other people's views or assessment towards them. In their view, individuals are free to do anything, free to express their wants and needs, especially when they are dealing with tourism activities. Therefore, in the context of individualistic community, Australian tourists tend to have a high intention to doing activities in tourism areas or during their vacation.

For the domestic tourists, on the other hand, they tend to have a collectivist culture, the behavior exhibited highly dependent on the views, opinions or values that exist within the group. Their behavior in the activities is largely determined by the behavior of the group; for the main interest belongs to the group. This may limit the freedom of the individual in a collectivist culture in expressing different behaviors out of the behavior of groups or behaviors that is tailed with the community. According to Riter in Pizam and Sussman [10], Japanese tourists (collectively) are not such pioneers or adventurers. Research by Kim and Lee in Manrai [26] indicated that the individualist tourists are more likely to look for new things, while collectivist tourists tend to be motivated to be with family. Veerapong [29], Vespestad and Mehmetoglu [30] found that individuals with individualist orientation values are more challenged to participate in the activities of nature and hiking. Similarly, other research showed that consumers from individualistic cultures showed a higher tendency to explore a variety of places and visit places that are completely different from the commonly encountered [31].

Individualism shows a more loose relationship between individuals with the societies, and each individual is expected only to keep himself and his immediate family. Collectivism, on the other hand, refers to a society or community in which the individuals are integrated into a strong, cohesive in-group, throughout the life of the community which will continue to protect them and not question loyalty within the group members [8]. The consequences of these values in consumers' behavior in tourism activities may relate to the behavior of the people in groups, their relationships with others and their perceptions of themselves in relation to others [32].

In collectivist culture, the orientation of the collectivity and identity are derived from the social system [33]. Therefore the people in this culture tend to be influenced by the behavior as referred to the group and see themselves as part of an integrated parts or members of the community. The empirical research so far has shown that individuals from such high collectivist culture tend to be family-oriented compared to those from high individualism culture. The study by Sun et al. [31] and Kosompong et al. [22] showed that consumers with collectivist value are more oriented to their families. Individuals' behavior exhibited by high collectivist value may indicates responsibilities as a member of the family, loyalty, and uphold the unity and happiness together in the family.

The strong bond that exists within the individuals and the group has consequences for the individual impulse to behave that can please the other group members, so that such behavior 
may improve the relationship within the individuals in the group. This study demonstrated that the behavior of domestic tourists who tend to like to buy souvenirs or handicrafts at tourist sites, buying the presents for family, friends or other individuals in the group, shopping, traveling in groups, and have a higher preference for sending message to the other people (through letter or postcard) to family members or other groups.

Long-term orientation/Confucian dynamism is the degree to which a culture which focus on the future. Individuals, who have a high orientation to get the memories of the past when they think about the past, are more prone to nostalgia and memories and tend to like to bring perceived in doing something including during the vacation. They feel comfortable in their memories and organize their behaviors in ways accordance with the past because they believe that the past experience would provide comfort, so individuals tend to hesitate to try new things in current life $[34,35]$. Consistent with this argument, Holbrook [34], Cotte et al. [36], Baumeister and Baumeister et al. in Karande and Merchant [35], found that individuals with a past orientation would have a strong preference for products and services that remind them of the past, avoiding the new or foreign recreational activities; they are more likely to remain on the existing routines and more less likely to act spontaneously.

The domestic tourists prefer the current behaviors that may be helpful for their future and better appreciate the past. The futureoriented perspective of the domestic tourists may cause their tendency to take into account the duration for their travel (most likely to travel in a relatively short time) because they have burden to be required to back to work in the origin place, setting the effort to prepare for the future. This view may also cause the domestic tourists will consider every dime they spent during the vacation, tend to work continuously even though at the time of traveling, so that in the end they are hesitant to interact with the surrounding environments during the vacations. The Australian tourists, on the other hand, who have a long-term orientation culture, have higher score in terms of duration of traveling, so they tend to be happy to get together, to spend money for pleasure; they travel with relatively longer duration. For those trips are something that should be filled with fun activities, recreations, add friends / acquaintances, trying new things, regardless their routines during this encounter. What obtained currently would be for life today.

Variable power distance culture is one of the explanatory variables on the tourists' interactions behaviors. Individuals with a view of the low power distance tend to take relationships with others in a way more consultative or democratic, respect the independence and their perspectives on other members of society tend to be the same on a formal position [8,37]. The domestic tourists have higher score of power distance scores compared to the Australian tourists. This means that more domestic tourists to have a sense of honor, respect of individuals who are in a higher position and tend to still pay attention to the social level (hierarchy) in view of other individuals, including during the vacation. This view tends to reduce domestic tourists' intention to interact with the surrounding environment including the new people whose status is unknown or even higher. Domestic tourists tend to shy away from activities which may not suit with their social status, such as eating in simple stalls, communicate with other individuals in which their view have a different social status. In addition, their social position or status for domestic tourists requires them to always be present in order to strengthen their status in the group. According to Woodside and Ahn [16] shorter duration visits are more likely to be conducted by the tourists from countries with high power distance. This is because if a person gets a high status in the hierarchical power structures then that individual must be physically present to strengthen its position continuously, whereas in countries with low power distance, weak social ties so that they can travel longer as they like.

\section{CONCLUSION}

The tourism behaviors of Australian and Indonesian tourists in doing activities, interactions, and transactions during the vacation in Lombok Island indicated some differences. The differences in behavioral intention that occurred between the groups of Australian and Indonesian tourists in activities can be explained based on the cultural background they have. Individuals with low uncertainty avoidance and individualistic values performed high behavioral intention activities. Similarly, individuals with low uncertainty avoidance value and low long-term orientation, and low power distance values had high intention to interactions. Individuals with collectivist orientation values and high 
uncertainty avoidance, on the other hand, had high behavioral intension to transaction.

\section{REFERENCES}

[1] Pizam, A., G. H. Jeong. 1996. Cross-cultural tourist behavior; perception of Korean tour-guides. Journal Tourism Management 17 (4), 277- 289.

[2] Reisinger, and Turner. 1997. Cross-cultural differences in tourism: Indonesian Tourists in Australia. Journal Tourism Management 18 (3), 139-147.

[3] Nuray, Li, Yusal. 2012. Cross cultural differences in purchase decision marketing criteria. International Journal of Culture, Tourism and Hospitality Research 6 (1), 3443.

[4] Yu, J. Y., and G. K. Tae. 2012. A cross-cultural study of perceptions of medical tourism among Chinese, Japanese and Korean tourists in Korea, Journal Tourism Management 33, 80e88.

[5] Woodside, H. Yun, and Marshall. 2011. General theory of cultures' consequences on international tourism behavior. Journal of Business Research 64.

[6] Pearce, L. P. 2005. Tourist behavior: themes and conceptual schemes. Cromwell Press.

[7] Schifman, L., and Kanuk. 2007. Consumer Behavior $7^{\text {th }}$ Ed. Kasip and Zoelkifli (Transl.). Perilaku Konsumen $7^{\text {th }}$ Ed. Indeks. Jakarta.

[8] Kotler, P. 2003. Marketing management $11^{\text {th }}$ Ed. International Edition. Prentice Hall.

[9] Hoftstede, G. 1991. Cultures and organizations, software of the mind. McGraw-Hill. New York.

[10] Pizam and Sussmann. 1995. Does nationality affect tourist behavior? Annals of Tourism Research 22 (4), 901-917.

[11] Reisinger, Y. 2009. Cross-cultural differences in tourist behavior: handbook of tourist behavior, theory and practice. Routledge: Taylor and Francis Group. New York-London.

[12] Meng, F. 2010. Individualism/coolectivism and group travel behavior: a cross-cultural perspective. International Jornal of Culture, Tourism, and Hospitality Research 4 (4), 340351.

[13] Bennet, Leo, and Hartel. 2005. Cross cultural differences in consumer decision making style. Cross-cultural Management 12 (3), 3261.

[14] Leng, Y. and Botelho. 2010. How does national culture impact on consumers' decision making styles? A cross cultural study in Brazil, the United States and Japan. BAR, Curitiba 7 (3), art. 3.

[15] Crotts, J., and R. Erdmann. 2000. Does national culture influence consumers' evaluation of travel services? A test of Hofstede's model of Cross-cultural differences, Managing Service Quality, Emerald Article, 10 (6), 410-419.

[16] Woodside and Ahn. 2008. Culture's consequences on experiencing international tourism services and products; Quantitattive and qualitative Fuzzy-set testing of an integrative of national culture applied to the consumption behaviours of Asian, European and North American consumers. Tourism Management. CAB International.

[17] Cho, S. Y. 1991. The ugly Koreans are coming?. Business Korea 9 (2), 25-31.

[18] Reisinger, Y. 2009. International tourism; cultures and behavior $1^{\text {st }}$ Ed. Elsiever Ltd.

[19] Yuksel, K. 2006. Cross-national analysis of hotel customers' attitude toward complaining and their complaining behaviour, Journal Tourism Management 27, 11-24.

[20] Yoo, Donthu, and Lenartowicz. 2011. Measuring Hofstede's five dimensions of cultural values at the individual level: development and validation of CVSCALE. Journal of International Consumer Marketing 23, 3-4.

[21] Keillor, B. D., G. Hult, M. Thomas, and D. Kandemir. 2004. A study of the service encounter in eight countries. Journal International Marketing 12 (1), 9-35.

[22] Kongsompong, Green, and Patterson. 2009. Collectivism and social influence in the buying decision: A four country study on Inter- and Intra-national differencess, Australasian Marketing Journal 17, 142-149.

[23] Patterson, P. G., E. Cowley, and K. Prasongsukarn. 2006. Service failure recovery: the moderating impact of individual-level value orientation on perceptions of justice. International Journal of Research in Marketing 23, 263-277.

[24] Reid, V. 2011. A study of the Influence of individual level culture value orientation on the formation of service quality expectations. PhD Thesis. University of Nottingham.

[25] Sekaran, Uma. 2003. Research methods for business $4^{\text {th }}$ Ed. Kwan, M. (Transl.). Metodologi Penelitian untuk bisnis Edisi 4, Buku 1 dan 2. Salemba Empat. Jakarta.

[26] Manrai and Manrai. 2011. Hofstede's cultural dimensions and tourist behaviors: a 
review and conceptual framework, Journal of Economics, Finance and Administrative Science 16 (31), 23-48.

[27] Yoon, J. O. 2007. An exploration of tourist shopping. PhD Thesis. A \& M University.

[28] Joanne, Y. J. Oh, and C. K. Cheng. 2004. Predictor of tourist shopping behaviour: examination of socio demographic characteristics and trip typologies. Journal of Vacation Marketing 10 (4).

[29] Veerapong, M. 2007. The use of collectivist and individualist culture as indicator for finding patterns of international tourist. The Business Review, Cambridge.

[30] Vespestead and Mehmetoglu. 2010. The relationship between tourist, nationality, cultural orientation and nature-based tourism experiences. European Journal of Tourism Research 21, 127-133.

[31] Sun, Horn, and Merritt. 2004. Values and lifestyles of individualists and collectivist: a study on Chinese, Japanese, British and US consumers, Journal of Consumer Marketing 21 (5).

[32] Jung, K. and K. Kao. 2004. Culture's influence on consumer behaviors: differences among ethnic groups in a Multiracial Asian Country. Advances in Consumer Research 31.

[33] Hofstede. 1980. Culture's consequences: international differences in work related values. SAGE. Beverly Hills.

[34] Holbrook. 1993. Nostalgia and consumption preferences: some emerging patterns of consumer research. Journal of Consumer Research 20, 245-256.

[35] Karande, K., and A. Merchant. 2012. The impact of time and planning orientation on an individual's recreational shopper identity and shopping behavior. Journal of Marketing Theory and Practice 20 (1), 59-72.

[36] Cotte, Ratneshwar, and Mick. 2004. The time of their lives: phenomenological and metaphorical characteristics of consumer time styles. Journal of Consumer Research 31 (2), 333-345.

[37] Reisinger and Turner. 1998. Cultural differences between Mandarin-speaking tourists and Australian hosts and their impact on cross-cultural tourist - host interaction. Journal of Business Research 42, 175-187. 